\title{
Protoporphyrin-induced Cholestasis in
}

\section{the Isolated In Situ Perfused Rat Liver}

\author{
Dennis L. Avner, Randall G. Lee, and Malcolm M. Berenson, Division \\ of Gastroenterology, Department of Internal Medicine, and Department \\ of Pathology, University of Utah College of Medicine, Salt Lake City, \\ Utah 84132; Salt Lake City Veterans Administration Medical Center, \\ Salt Lake City, Utah 84148
}

\begin{abstract}
A B S TRACT The pathogenesis of liver disease in protoporphyria has been presumed to result from the hepatic deposition of protoporphyrin. To examine the effects of protoporphyrin on hepatic bile flow and histopathology, studies were performed employing an isolated, in situ, rat liver perfusion system. Rat livers in the control group were perfused with $0-80 \mu \mathrm{mol}$ sodium taurocholate/h. Rat livers in the experimental group were perfused with sodium taurocholate and (a) sufficient quantities of protoporphyrin to produce maximal canalicular secretion and $(b)$ perfusate protoporphyrin concentrations of $0.01,0.1$, and $1 \mu \mathrm{M}$.
\end{abstract}

The administration of protoporphyrin sufficient to achieve maximal canalicular secretion was found to significantly reduce bile flow in rats infused with 0 , 40 , and $80 \mu \mathrm{mol}$ sodium taurocholate/h. Linear regression analysis defined the relationship between bile flow and biliary bile acid secretion and showed that the bile acid-independent fraction of bile flow was reduced $(P<0.01)$. Bile acid-dependent flow was unaffected and there was no significant difference in biliary bile acid secretion rates between control and protoporphyrin-perfused livers. Perfusion of rat livers with varying concentrations of protoporphyrin demonstrated the reduction of bile flow was dose-related. Analysis of perfusate enzyme activity did not reveal abnormalities that could account for the cholestasis. Studies to evaluate the effect of protoporphyrin on regional hepatic hemodynamics were inconclusive.

Histopathological studies of control and protoporphyrin-perfused rat livers did not show ab-

This study was presented, in part, at the Annual Meeting of the American Association for the Study of Liver Diseases, 7-8 November 1979 and was published in abstract form in 1979. Gastroenterology. 77(5): A2.

Address reprint requests to Dr. Avner at the University of Utah.

Received for publication 26 February 1980 and in revised form 16 October 1979. normalities on light microscopy. However, canalicular dilatation, distortion, and loss of microvilli were present in the protoporphyrin-perfused livers examined by transmission electron microscopy. Although ultraviolet microscopy showed diffuse fluorescence of the hepatocytes and canaliculi of protoporphyrinperfused livers, the deposition of protoporphyrin in amorphous or crystalline forms was notably absent in studies with polarizing and transmission electron microscopy.

These studies provide evidence that protoporphyrin has hepatotoxic properties that affect the canalicular secretory apparatus. The mechanism(s) responsible for the injury require further clarification.

\section{INTRODUCTION}

Protoporphyria is an inherited disorder of porphyrin metabolism in which deficiency of heme synthase leads to overproduction of protoporphyrin (1-5). The initial manifestation and dominant symptom of the disorder is a photodermatitis characterized by erythema, edema and pain $(1,6,7)$. However, gallbladder and liver disease are now recognized to be the most serious consequences of the illness. Gallstones have often been reported in patients with protoporphyria and have occurred at an unusually early age $(7,8)$. Cirrhosis and liver failure are singularly responsible for death that results from the disorder $(9-11)$.

15 deaths from liver failure have been reported in patients with protoporphyria involving both sexes ranging in age from 11 to $60 \mathrm{yr}(9-15)$. Histopathologic examination of the liver in these cases has revealed cholestasis, periportal fibrosis, and micronodular cirrhosis. This is associated with brownishblack pigmentation and deposition of granular and globular pigment in hepatocytes, canaliculi and Kupffer cells $(9,10,16,17)$. The pigment has been shown to represent deposits of amorphous and 
crystalline protoporphyrin by fluorescent $(8,9)$, polarizing $(9,16,18)$, and electron microscopy $(9,16,17,19)$. These findings have been corroborated by demonstrating protoporphyrin accumulation in massive amounts ranging from 0.2 to $57.5 \mathrm{mg} / \mathrm{g}$ wet liver (10).

The pathogenesis of the liver disease in protoporphyria is not clearly understood. In part, this is because of lack of a suitable animal model. Liver disease with histopathology resembling that seen in patients with protoporphyria has been produced by administering porphyrinogenic agents, e.g., griseofulvin, to mice $(20-22)$. Unfortunately this has not proved particularly valuable in addressing the nature of protoporphyrin deposition in the liver as it applies to cases of protoporphyria in humans (23), except in cases in which the liver is primarily responsible for protoporphyrin overproduction (24). The recent demonstration of a bovine form of protoporphyria may provide a more meaningful model to clarify many aspects of the disorder (25).

Because protoporphyrin is primarily eliminated by the liver, characterization of its disposal may provide an understanding of the factors responsible for its accumulation. In an isolated in situ liver perfusion system, protoporphyrin was rapidly cleared from perfusate by the liver but biliary excretion was limited (26). In those studies and subsequent investigation of the maximal canalicular secretion of protoporphyrin (27), it was observed that bile flow was reduced in rat livers perfused with protoporphyrin. Therefore, studies were designed to examine the specificity and significance of this phenomenon. Results of these studies provide evidence that protoporphyrin induces cholestasis in the isolated, in situ, perfused rat liver unassociated with the use of porphyrinogenic agents or with deposition of amorphous or crystalline protoporphyrin.

\section{MATERIALS}

Animals and operative procedure. Nonfasting male Sprague-Dawley rats (Holtzman Laboratories, Madison, Wis.) weighing 250-350 g and fed standard laboratory chow (Simonson Laboratories, Gilroy, Calif.) were used in all experiments. A modification of the techniques of Miller et al. (28) and Hems et al. (29) was used to prepare rats for the isolated in situ liver perfusion. After ether anesthesia, the abdomen was opened through a midline incision and the portal anatomy exposed. The common bile duct was cannulated near its entrance into the duodenum with bevelled PE 10 polyethylene tubing (Clay Adams, Parsippany Div., Beckton, Dickinson \& Co., N. J.) which was inserted to a point just short of the bifurcation of the duct. The portal vein was cannulated with a 14 gauge $(1.8-\mathrm{mm}$ i.d.) Cathlon IV angiocath (Jelco Laboratories, Raritan, N. J.), immediately flushed with 5-10 $\mathrm{ml}$ heparinized saline, and secured in place. The anterior thoracic rib cage was then excised and a 14-gauge angiocath inserted into the intra- thoracic portion of the inferior vena cava via the right artrium. Residual hepatic blood was removed by injecting $5-10 \mathrm{ml}$ of heparinized saline into the portal vein catheter after ligating the inferior vena cava above the right renal vein. The isolated in situ preparation was then moved to a prewarmed plexiglass cabinet and connected to the perfusion apparatus. The time interval between interruption of the portal circulation to onset of artificial perfusion was $<3.5 \mathrm{~min}$. Experiments were discontinued if interruption of the portal circulation was prolonged, media leaked from the liver, the gross appearance of the liver suggested nonhomogeneous perfusion, or conditions of the experiment were unexpectedly altered in any way.

Perfusion apparatus, media, and experimental conditions. The entire perfusion apparatus was contained within a plexiglass cabinet $(0.9 \times 0.6 \times 0.6 \mathrm{~m})$. The apparatus was designed to recirculate $100 \mathrm{ml}$ of oxygenated media at a constant rate through the liver. Liver perfusion occurred in the following way: media was pumped (Masterflex multihead peristaltic pump 7545-10, Cole Parmer Instrument Co., Chicago, Ill.) from a receptacle to a membrane oxygenator. Oxygenation of the media was accomplished by passing it through $4.57 \mathrm{~m}$ of silastic tubing (i.d. $1.47 \mathrm{~mm}$; o.d. 1.96 $\mathrm{mm}$, Dow Corning Corp., Midland, Mich.) coiled in a glass jar that was suffused with $5 \% \mathrm{CO}_{2}$ and $95 \% \mathrm{O}_{2}$ flowing at 3 liters/min. Before entering the portal vein the oxygenated media was passed through a flowmeter (No. 12, Gibco Laboratories, Grand Island Biological Co., Grand Island, N. Y.). A constant perfusate flow rate of $40 \mathrm{ml} / \mathrm{min}$ was maintained by appropriately setting the pump speed. This system obviated the potentially variable rate of perfusion in gravity-dependent flow systems. Media exiting the liver was directed back to the receptacle for recirculation. An alternate media contained in a separate reservoir, circulated by means of the multichannel peristaltic pump, could be substituted by manipulation of a y-piece connector without interruption of flow to the liver. The plexiglass cabinet containing the perfusion apparatus was humidified, prewarmed, and maintained at $37^{\circ} \mathrm{C}$ with a fan-heater. The perfusion apparatus and tubing were washed with deionized water before and after each perfusion.

The perfusion media consisted of Krebs-Henseleit solution (30) to which $3 \%$ bovine albumin (Fraction V, Sigma Chemical Co., St. Louis, Mo.), protoporphyrin IX (Porphyrin Products, Logan, Utah) and sodium taurocholate (NaTC, ${ }^{1}$ Steraloids, Inc., Milton, N. H.) were added. Erythrocytes were not added to the perfusate because of their ability to absorb protoporphyrin. A stock solution of KrebsHenseleit solution with $3 \%$ bovine albumin was prepared by passing it through a $0.45-\mu \mathrm{m}$ filter (Millipore Corp., Bedford, Mass.), adjusting the $\mathrm{pH}$ to 7.43 and adding gentamicin, $1 \mathrm{ml} / \mathrm{liter}$ (Schering Corp., Kenilworth, N. J.). The stock solution was refrigerated at $4^{\circ} \mathrm{C}$ and appropriate amounts warmed prior to use. The protoporphyrin, which was added to the stock solution of perfusion media, was prepared on the day of use from a supply of purified material refrigerated at $4^{\circ} \mathrm{C}$ and protected from light. A solution of protoporphyrin was made by dissolving $5-7 \mathrm{mg}$ in $0.5 \mathrm{ml} 1 \mathrm{~N} \mathrm{NH} \mathrm{N}_{4} \mathrm{OH}$, diluting it to $10 \mathrm{ml}$ with $\mathrm{D}_{5} \mathrm{~W}$ and filtering it through a $0.45-\mu \mathrm{m}$ Millipore filter. The osmolarity of this solution was $\sim 280$ mosmol. The concentration of protoporphyrin in the filtered solution was determined spectrophotometrically using a Carey model 15 spectrophotometer (Varian Associates Inc., Palo Alto, Calif.).

'Abbreviations used in this paper: BAIF, bile acidindependent fraction; NaTC, sodium taurocholate. 
Appropriate amounts of this concentrated solution of protoporphyrin (550-650 $\mu \mathrm{g} / \mathrm{ml}$ ) were added by bolus or constant syringe-pumped infusion (Harvard pump 940, Harvard Apparatus Co., Inc., St. Natick, Mass.) to the perfusion media to obtain concentrations desired in the experimental studies. During circulation of media containing protoporphyrin, glassware and tubing were wrapped in aluminum foil to reduce exposure to light. NaTC was found to be $>98 \%$ pure by thin layer chromatography (31). After dissolving in normal saline, NaTC was syringepumped into the perfusion media at a constant rate varying from 2-80 $\mu \mathrm{mol} / \mathrm{h}$ through a port in the receptacle. The media was magnetically stirred and the $\mathrm{pH}$ continuously monitored (Radiometer PHM 63, digital pH meter, London Co., Westlake, Ohio) and maintained between 7.41-7.43 by frequent manual addition of minute amounts of concentrated sodium bicarbonate.

The isolated in situ liver perfusions were maintained for $90 \mathrm{~min}$. During the initial $20 \mathrm{~min}$, which was considered the basal equilibration period, livers were perfused only with the Krebs-Henseleit solution containing albumin. For the remaining $70 \mathrm{~min}$, the control group of livers were perfused with and without solutions containing NaTC; protoporphyrin was added in the experimental group. Immediately after perfusion, livers were removed from the abdomen, gently blotted, weighed, and processed for histologic and analytic studies.

Studies of viability and function. The functional integrity of the isolated perfused rat liver was assessed by measurement of bile flow, oxygen consumption, and glucose synthesis. Structural integrity was assessed histologically. Bile flow was determined by measurement of bile volumes at 10-min intervals. Bile volume was measured using calibrated micropipettes (Clay Adams Div.) which were compared with weighed standards and found to be accurate to within $\pm 2 \mu$ l. Three control perfusions showed a bile flow of $0.050 \pm 0.002 \mathrm{ml} / \mathrm{h}$ per $\mathrm{g}$ wet liver (mean $\pm \mathrm{SEM})$. The bile flow rate is consistent with values reported by other investigators employing similar techniques $(29,32)$. Oxygen consumption was determined from the $\mathrm{PO}_{2}$ difference between pre- and postliver samples of perfusion media collected anaerobically in heparinized, iced, glass syringes after 30, 45, and $60 \mathrm{~min}$ of perfusion. The $\mathrm{PO}_{2}$ was analyzed with a Radiometer BMS 3 MK 2 blood gas machine (London Co.). Oxygen consumption was determined according to the equation: oxygen consumption $=\mathrm{K}\left(\mathrm{O}_{2}\right)$ $\times F$, where $K=$ solubility coefficient of oxygen in plasma, $0.00126 \mathrm{mmol} / \mathrm{liter} ; \mathrm{O}_{2}=$ portal-caval $\mathrm{O}_{2}$ difference in $\mathrm{mm}$ $\mathrm{Hg}$; and $\mathrm{F}=$ flow rate, $\mathrm{ml} / \mathrm{min}$ per $\mathrm{g}$ wet liver (33). The average $\mathrm{O}_{2}$ consumption was $1.73 \pm 0.03 \mu \mathrm{mol} \mathrm{O}_{2} / \mathrm{min}$ per g wet liver (mean $\pm \mathrm{SEM}$ ). The $\mathrm{O}_{2}$ consumption was $\sim 80 \%$ of that reported for isolated perfused rat liver studies employing hemoglobin as an $\mathrm{O}_{2}$ carrier $(29,34)$. Glucose synthesis by the perfused liver was determined by examining the production of glucose from lactate. This was accomplished by depleting glycogen stores in the liver during $30 \mathrm{~min}$ of perfusion, adding $10 \mathrm{mM}$ lactate to the media and measuring glucose concentration in media taken from the reservoir 15 and 30 min later. Glucose concentration was measured with the coupled enzyme method of Slein (35), using hexokinase and glucose-6-phosphate dehydrogenase (Statzyme glucose, Worthington Biochemical Corp., Freehold, N. J.). The glucose synthesis rate in control rat liver perfusions $(n=3)$ was $1.00 \pm 0.05 \mu \mathrm{mol}$ glucose $/ \mathrm{min}$ per $\mathrm{g}$ wet liver (mean $\pm \mathrm{SEM}$ ). This synthesis rate is comparable to values reported by Hems et al. (29). Tissue from three control liver perfusions were processed for light, scanning, and electron microscopy as described below in the section on histopathology. Light microscopy revealed normal architecture and no evidence of edema, cell necrosis, or inflammation. The sinusoids, canalicular apparatus, and hepatocyte organelles did not show significant abnormalities when examined by scanning and electron microscopy. Vacuoles were present in some hepatocytes $(36,37)$.

Studies of bile flow and bile acid secretion. Bile volumes were determined as previously described in studies on liver viability and function. All livers were perfused with Krebs-Henseleit solution containing albumin for a 20 min basal period. Three types of studies were then performed. In the first study, the control group of livers were perfused with solutions to which 0,40 , or $80 \mu \mathrm{mol} \mathrm{NaTC} / \mathrm{h}$ were infused. Livers in the experimental group were perfused with similar solutions with the addition of protoporphyrin. Protoporphyrin was administered as a $1 \mu \mathrm{mol}$ bolus followed by a constant syringe-pumped infusion of $0.05 \mu \mathrm{mol}$ protoporphyrin/min to establish maximal canalicular transport (38). Pilot studies indicated that the infused amount of protoporphyrin, after a $1 \mu \mathrm{mol}$ bolus, was the minimum dosage sufficient to establish a constant or slowly rising perfusate protoporphyrin concentration $(3-5 \mu \mathrm{g} / \mathrm{ml})$ during the last $50 \mathrm{~min}$ of perfusion. In the second study, the control group of livers $(n=31)$ were perfused with solutions to which 2-80 $\mu \mathrm{mol} \mathrm{NaTC/h}$ was added. Livers in the experimental group $(n=37)$ were perfused with similar solutions but with the addition of the same amounts of protoporphyrin as administered in the first studies. In the third study, the control group of livers $(n=5)$ were perfused with solutions containing no NaTC; the experimental livers $(n=3)$ were perfused with solutions to which a single bolus of protoporphyrin was added to achieve perfusate concentrations of $1,0.1$, and $0.01 \mu \mathrm{M}(5,0.5$, and $0.05 \mathrm{mg} /$ $\mathrm{ml}$, respectively). $\left[{ }^{14} \mathrm{C}\right]$ erythritol clearances were not used to measure canalicular bile flow because it has been shown previously that bile formation in the isolated perfused rat liver is entirely dependent on canalicular flow (34). To compare bile flow between rats, bile volumes secreted during the experimental period of perfusion were expressed as a percentage of the basal $20 \mathrm{~min}$ period, which was assigned a value of $100 \%$.

Bile acid secretion was determined by analyzing the bile acid output for the last $70 \mathrm{~min}$ of liver perfusion. Bile acid samples were immediately frozen after collection and stored at $-20^{\circ} \mathrm{C}$. Bile acid analysis was made according to the method of Iwata and Yamasaki (39) employing 2-hydroxysteroid dehydrogenase (Worthington Biochemical Corp.) and NADH (Sigma Chemical Co.).

Studies of regional hepatic perfusion. Regional hepatic perfusate flow was assessed at the conclusion of perfusions (90 min) with and without protoporphyrin by determining the distribution of technetium-99m-labeled human albumin microspheres, 10-35 $\mu \mathrm{M}$ in Diam (3M Co., St. Paul, Minn.), according to the technique described by Tavoloni et al. (40). A total of 10-15,000 microspheres containing 4-5,000 $\mu \mathrm{Ci}$ mixed in $1 \mathrm{ml}$ of perfusion media were injected just proximal to the portal vein within $10 \mathrm{~s}$. 2 min later the perfusion was stopped. The livers were then photographed, in situ, using a gamma scintillation camera (Siemens Corp., Iselin, N. J.) with a pinhole collimator, and radioactivity in 50-100 mg tissue samples obtained from peripheral and central areas of left, median, caudate, and right (pyramidal) lobes determined in a well counter (Baird Corp., Bedford, Mass.). The regional hepatic lobar flow was expressed as a ratio of peripheral/central radioactivity.

Perfusate aspartate aminotransferase and lactic dehydrogenase activities. The activities of aspartate aminotransferase and lactic dehydrogenase were determined by 


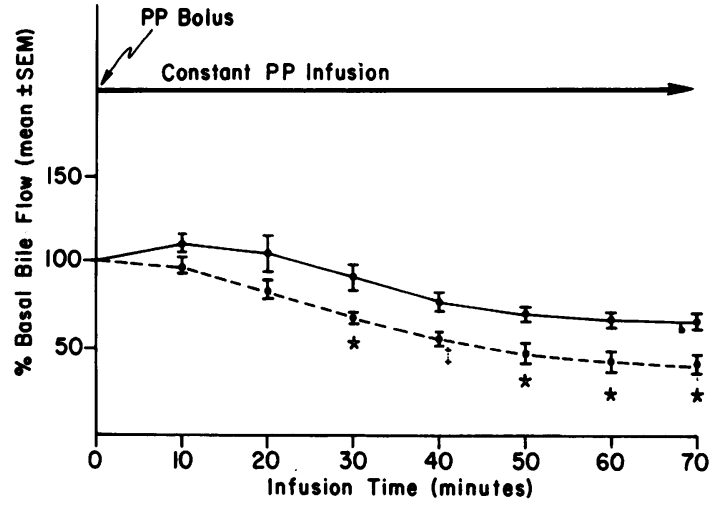

FIGURE 1 Effect of protoporphyrin in perfusion solutions on bile flow in the in situ, isolated perfused rat liver without NaTC infusion: control vs. protoporphyrin-perfused rat livers. Protoporphyrin (PP) was administered as a $1-\mu \mathrm{mol}$ bolus followed by a constant infusion of $0.05 \mu \mathrm{mol}$ protoporphyrin/min. Each point represents the mean \pm SEM for a 10-min interval of bile flow, expressed as a percentage of basal bile flow. The basal bile flow rate (microliters per minute per gram liver) determined for a 20-min period $(-20-0 \mathrm{~min})$ was assigned a value of $100 \%$. After $30 \mathrm{~min}$ of perfusion with protoporphyrin $(n=5$; broken line), significant inhibition of bile flow occurred when compared to controls $(n=5$; solid line). Statistical significance is indicated by symbols, ${ }^{*} P<0.05 ; \ddagger P<0.01$.

standard techniques (41-43) in $200 \mu \mathrm{l}$ samples of perfusate at $0,10,20,40$, and 70 min during control $(n=7)$ and protoporphyrin perfusions $(n=10)$. Mean enzyme activity for the total perfusion period was used to assess differences between control and protoporphyrin-perfused livers.

Histopathologic studies. Samples of liver tissue from the central area of the left lobe of control and protoporphyrinperfused livers, without the infusion of NaTC, were processed for light, fluorescent, polarizing, scanning, and electron microscopy. Samples were fixed in either $10 \%$ buffered formalin or cold Karnofsky's fixative or frozen at $-70^{\circ} \mathrm{C}$. Light microscopy was performed on $4-\mu \mathrm{m}$ sections of liver tissue stained with hematoxylin and eosin. Unstained sections were viewed under ultraviolet light with a Zeiss universal fluorescent microscope (Carl Zeiss, Inc., New York) using BG-38 and UG-1 excitation filters. Tissue sections were also examined under polarization (polarizing lens; Carl Zeiss, Inc.,). Tissue for scanning and electron microscopy was prepared in the laboratory of Dr. F. Moatamed at the Veterans Administration Hospital, Salt Lake City, Utah. Specimens for scanning electron microscopy, obtained from comparable areas of control and protoporphyrin-perfused livers, were hand sectioned (fractured), rinsed in $0.1 \mathrm{M}$ phosphate buffer, and postfixed in $1 \%$ osmium tetroxide. After ethanol dehydration, the tissue was dried with liquid $\mathrm{CO}_{2}$, mounted on scanning electron microscopy stubs and coated with gold. Tissue was examined with a JEOL JSM-35 scanning electron microscope (JEOL, USA. Electron Optics Div., Medford, Mass.) at $\times 130-15,000$. For transmission electron microscopy, $1-\mu \mathrm{m}$ thick sections were stained with toludine blue and used to trim tissue blocks to within a 12 cell radius around a central vein. These areas contained midzonal hepatocytes, as defined by Loud (44), as well as centrolobular cells. 10 sections were prepared from the selected blocks. Five electron micrographs were taken per block at $\times 5,000(\mathrm{JEOL} 100 \mathrm{CX}$ transmission electron microscope) and photographically enlarged to $\times 13,750$. The areas photographed were selected randomly with a viewing screen just touching two edges of the copper grid, as described by Weibel et al. (45). The volume density of the biliary space was determined by superimposing a double lattice test system over the micrographs and counting the fraction of points lying within the biliary space $(45,46)$. Additionally, ultrastructural observations were made at magnifications up to $\times 181,500$. These electron micrographic studies were performed by a pathologist (Dr. Lee) on coded specimens.

Statistical methods. The Student's $t$ test was used to compare the percent change in bile flow between corresponding periods of control and protoporphyrin-perfused livers. It was also employed to compare differences in bile acid secretion, volume density of the biliary space, perfusate enzyme activity, and regional hepatic perfusion between these groups. Linear regression analysis was performed on the straight portion $(30-70 \mathrm{~min})$ of the percentage of basal bile flow curves for control and protoporphyrin-perfused livers. The derived $y$-intercepts and slopes were analyzed by the $F$ test for statistical differences. Linear regression analysis was also used to derive best-fit lines describing the relationship of bile flow and bile acid secretion for control and protoporphyrin-perfused livers. Correlation coefficients were derived from linear regression analysis (47).

\section{RESULTS}

Effect of protoporphyrin on bile flow and biliary bile acid secretion with and without NaTC infusion. The effect of perfusion of protoporphyrin on bile flow without infusion of NaTC is illustrated in Fig. 1. Livers perfused with protoporphyrin had a significant reduction of bile flow compared to controls within $30 \mathrm{~min}$ and this reduction persisted throughout the remainder of the perfusion. The effect of perfusion of protoporphyrin during infusion of 40 $\mu \mathrm{mol} \mathrm{NaTC/h}$ (physiologic amounts) and $80 \mu \mathrm{mol}$ $\mathrm{NaTC} / \mathrm{h}$ on bile flow is shown in Figs. 2 and 3. Infusion of NaTC was found to produce the expected increase in bile flow in all perfusions. However, livers perfused with protoporphyrin had significantly less flow when compared to controls. The degree of inhibition of bile flow in protoporphyrin plus NaTC perfused livers was not significantly different from livers perfused with protoporphyrin alone. The results of linear regression analysis of the percentage of basal bile flow (30-70 min) for the control group vs. the protoporphyrinperfused group is shown in Table I. In each case, the $y$-intercepts for the livers perfused with protoporphyrin were significantly lower than controls, whereas the slopes did not differ significantly.

Biliary bile acid secretion was measured during perfusions with and without protoporphyrin as described in Methods, and results are shown in Table II. Livers perfused with NaTC had minimal bile acid secretion. Infusion of $40 \mu \mathrm{mol} \mathrm{NaTC} / \mathrm{h}$ resulted in biliary bile acid secretion comparable to that reported by Boyer (34), indicating that the isolated 


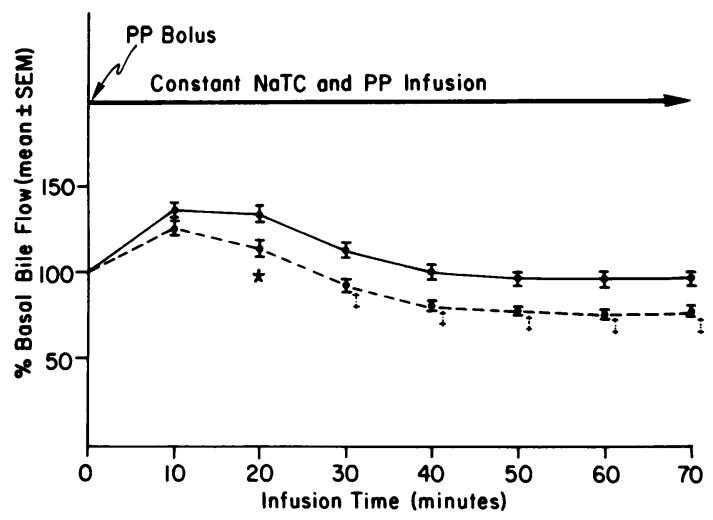

FIGURE 2 Effect of protoporphyrin in perfusion solutions on bile flow in the in situ, isolated perfused rat liver with 40 $\mu \mathrm{mol} \mathrm{NaTC/h}$ : control vs. protoporphyrin-perfused rat livers. Protoporphyrin (PP) was administered and the percentage of basal bile flow plotted as described in Fig. 1. After $20 \mathrm{~min}$ of perfusion with protoporphyrin $(n=5$; broken line), significant inhibition of bile flow occurred when compared to controls ( $n=5$; solid line). Statistical significance is indicated by symbols, ${ }^{*} P<0.05 ; \sharp P<0.01$.

perfused rat liver was capable of efficient bile acid clearance. Bile acid secretion rates for control and protoporphyrin-perfused livers were not significantly different when adjusted for liver weights.

Effect of protoporphyrin on the relationship of bile flow and biliary bile acid secretion. The relationship of bile flow and biliary bile acid secretion for the groups of livers perfused with and without protoporphyrin is shown in Fig. 4. Linear regression analysis was employed to derive best-fit lines for the two groups. A

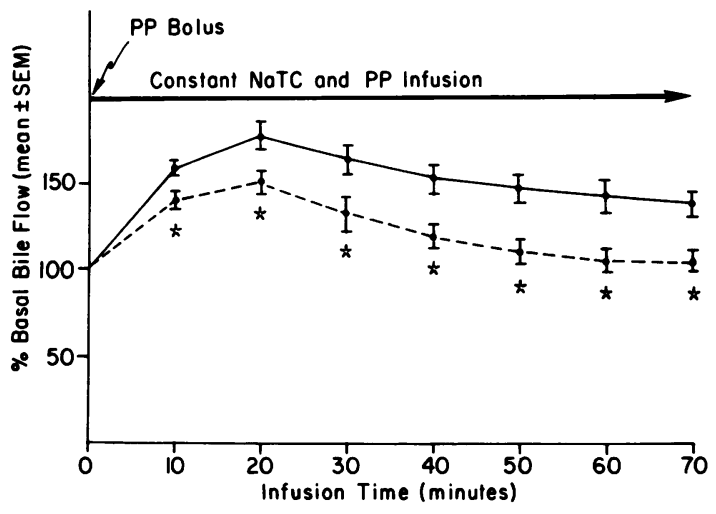

FIGURE 3 Effect of protoporphyrin in perfusion solutions on bile flow in the in situ, isolated perfused rat liver with $\mathbf{8 0}$ $\mu \mathrm{mol} \mathrm{NaTC/h}$ : control vs. protoporphyrin perfused rat livers. Protoporphyrin (PP) was administered and the percentage of basal bile flow plotted as described in Fig. 1. Within 10 min of perfusion with protoporphyrin $(n=5$; broken line), significant inhibition of bile flow occurred when compared to controls $(n=5$; solid line). Statistical significance is indicated by the symbols, ${ }^{*} P<0.05 ; \ddagger P<0.01$.
TABLE I

Linear Regression Analysis of the Percentage of Basal Bile Flow: Control vs. Protoporphyrin-Perfused Rat Livers

\begin{tabular}{lccccc}
\hline Perfusion groups & NaTC & $n$ & $y$-intercept & Slope & $\mathrm{r}$ \\
\hline & $\mu m o l / h$ & & & & \\
& 0 & 5 & 98.6 & -0.76 & -0.68 \\
Control & 0 & 5 & $77.6^{*}$ & -0.83 & -0.81 \\
Protoporphyrin & 40 & 5 & 123.5 & -0.69 & -0.74 \\
Control & 40 & 5 & $102.9^{*}$ & -0.64 & -0.77 \\
Protoporphyrin & 80 & 5 & 176.0 & -1.00 & -0.53 \\
Control & 80 & 5 & $142.0^{*}$ & -0.88 & -0.66 \\
Protoporphyrin & & & & & \\
\hline
\end{tabular}

Linear regression analysis was performed on the points representing the percent of basal bile flow, for 10-min intervals, between 30-70 min (the straight portion of curve) of control and protoporphyrin-perfused livers infused with and without NaTC. Protoporphyrin and NaTC were infused as described in Figs. 1-3. The $y$-intercepts of the controls were significantly greater than protoporphyrin-perfused rat livers. The asterisks indicate a $P<0.01$, control vs. protoporphyrinperfused rat livers.

direct correlation of bile flow and biliary bile acid secretion was indicated by $r$ values of 0.83 and 0.84 for the control group and protoporphyrin-perfused group, respectively. The bile acid-independent fraction (BAIF) of bile flow, indicated by the $y$-intercept, for the control group was $0.97 \mu \mathrm{l} / \mathrm{min}$ per $\mathrm{g}$ liver. In contrast, the BAIF of bile flow for the group treated with protoporphyrin was significantly $(P<0.01)$ reduced to 0.70 . There were no significant differences between the slopes of the two lines (control, -0.79 ; protoporphyrin-perfused, -0.77 ). The ratio of

TABLE II

Effect of Protoporphyrin on Biliary Bile Acid Secretion with and without NaTC Infusion: Control vs. Protoporphyrin-Perfused Rat Livers

\begin{tabular}{lccc}
\hline Perfusion groups & $n$ & NaTC & $\begin{array}{c}\text { Biliary bile acid } \\
\text { secretion }\end{array}$ \\
\hline & & $\mu m o l / h$ & $\mu$ mol/min/gliver \\
Control & 5 & 0 & $0.003 \pm 0.000$ \\
Protoporphyrin & 5 & 0 & $0.002 \pm 0.000$ \\
Control & 5 & 40 & $0.050 \pm 0.000$ \\
Protoporphyrin & 5 & 40 & $0.050 \pm 0.000$ \\
Control & 5 & 80 & $0.080 \pm 0.000$ \\
Protoporphyrin & 5 & 80 & $0.070 \pm 0.010$ \\
\hline
\end{tabular}

Biliary bile acid secretion (mean $\pm \mathrm{SEM}$ ) during isolated, in situ, rat liver perfusions. NaTC was infused at 0,40 , and 80 $\mu \mathrm{mol} / \mathrm{h}$ with and without perfusion of protoporphyrin sufficient to achieve maximal canalicular secretion $(1-\mu \mathrm{mol}$ bolus plus a constant infusion of $0.05 \mu \mathrm{mol}$ protoporphyrin $/ \mathrm{min}$ ). At each rate of $\mathrm{NaTC}$ infusion, differences between the control and protoporphyrin-perfused groups were not statistically significant. 


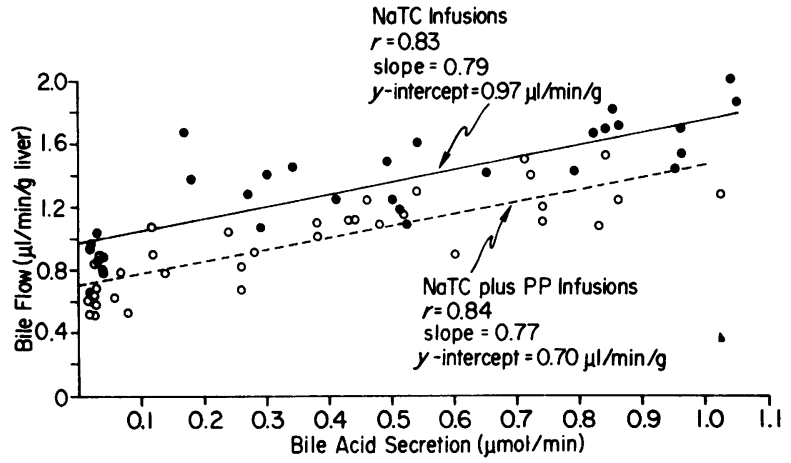

FIGURE 4 Correlation of bile flow and bile acid secretion during 0-80 $\mu \mathrm{mol}$ NaTC infusion in the in situ, isolated perfused rat liver with and without protoporphyrin. Each point represents the bile flow rate for a separate $70 \mathrm{~min}$ liver perfusion. Solid circles indicate controls without protoporphyrin $(n=31)$. Open circles indicate protoporphyrin-perfused rats $(n=37)$. Protoporphyrin was administered as described in Fig. 1. Linear regression analysis is shown by the solid (control) and broken lines (protoporphyrin-perfused). There is a significant difference $(P<0.01)$ between the $y$-intercepts of the groups; but no difference in slopes. This indicates an inhibitory effect of protoporphyrin on the BAIF of bile flow.

the BAIF of bile flow to total bile flow in the control group was comparable to that reported by Boyer (34).

Effect of varied protoporphyrin concentrations on bile flow. The effect of liver perfusion with varying concentrations of protoporphyrin on bile flow is presented in Fig. 5. The protoporphyrin bolus that achieved $0.01 \mu \mathrm{M}$ reduced bile flow but was not significantly different from controls. The protoporphyrin bolus that achieved $0.1 \mu \mathrm{M}$ significantly reduced bile flow compared with the control group within $20 \mathrm{~min}$ and persisted throughout the perfusion. Similarly, the protoporphyrin bolus that achieved a concen-

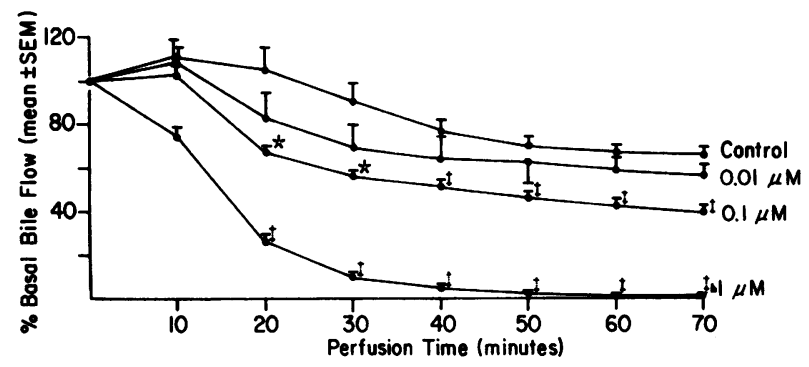

FIGURE 5 Effect of varying perfusate concentrations of protoporphyrin (without NaTC) on bile flow. Protoporphyrin was administered as a single bolus to achieve perfusate concentrations of $0.01,0.1$, and $1 \mu \mathrm{M}$. Bile flow was plotted as the percentage of basal bile flow as described in Fig. 1. Bile flow was reduced in rat livers perfused with protoporphyrin ( $n=3 /$ concentration) compared to controls $(n=5)$, and decreased as a function of protoporphyrin concentration. However, it was significantly different than controls only at protoporphyrin concentrations of 0.1 and $1 \mu \mathrm{M}$ as indicated by the symbols, ${ }^{*} P<0.05 ; \square P<0.01$.
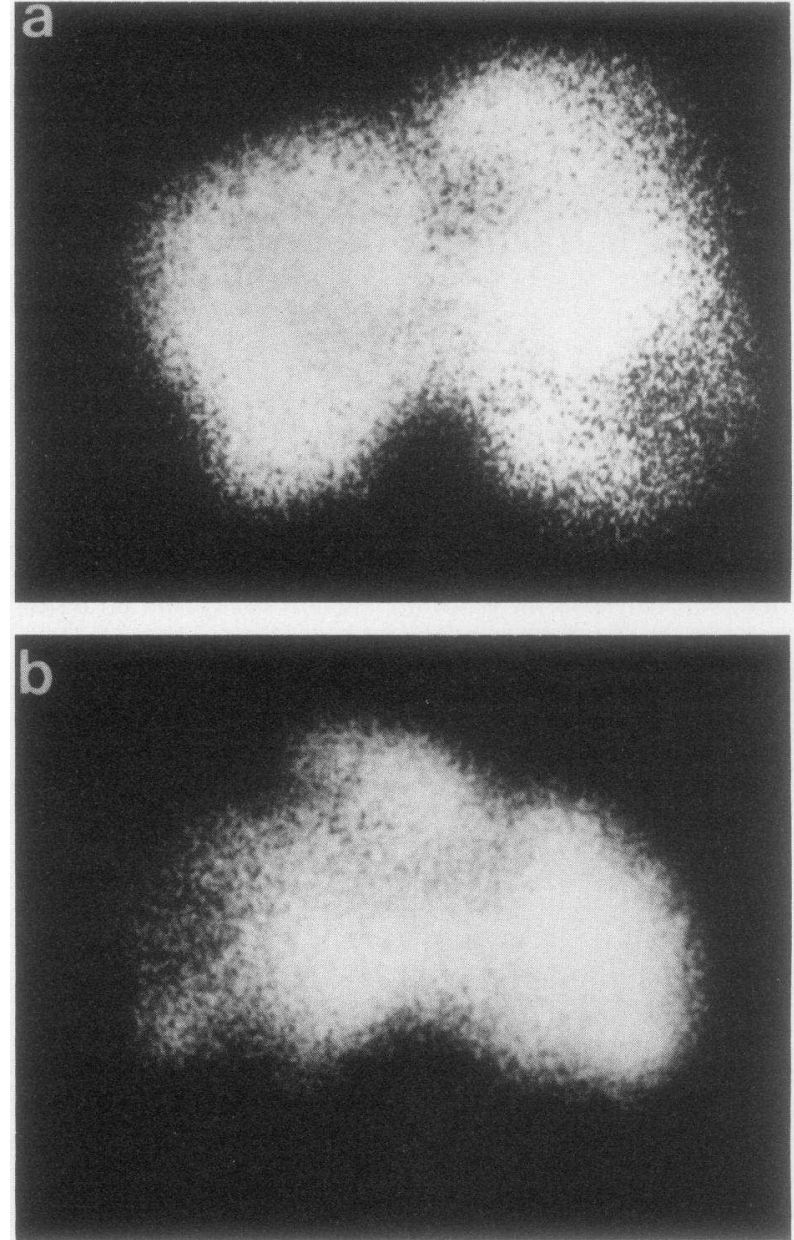

FIGURE 62 min after injection of radiolabeled microspheres, livers, in situ, were positioned $5 \mathrm{~cm}$ beneath a scintillation camera for 200,000 counts. (a) Control liver: relative homogeneity is apparent. (b) Protoporphyrin-perfused liver: both central and peripheral defects can be seen.

tration of $1 \mu \mathrm{M}$ markedly inhibited bile flow within 20 min when compared to the control group and essentially stopped all bile flow after $\mathbf{4 0} \mathrm{min}$ of perfusion.

Effect of protoporphyrin on regional hepatic perfusion. Representative technetium-99m-labeled human albumin microsphere scans for control and protoporphyrin-perfused livers are shown in Fig. 6 . The scans of control livers were relatively homogeneous, although both central and peripheral defects were variably observed. Livers perfused with protoporphyrin showed more nonhomogeneity than controls, but neither a preponderance of central nor peripheral defects could be appreciated. Results of the quantitative analysis of radiolabeled microsphere distribution is presented in Table III. Comparison of the mean ratio of peripheral/central radioactivity failed to discriminate significant differences be- 
tween the lobes of control and protoporphyrinperfused livers.

Effect of protoporphyrin on perfusate transaminase and lactic dehydrogenase activity. The activity of aspartate aminotransferase in perfusate during constant infusion of protoporphyrin was $6.39 \pm 1.79$ $\mathrm{U} /$ liter (mean $\pm \mathrm{SEM}$ ) and after a bolus of $1 \mu \mathrm{M}$ protoporphyrin was $6.30 \pm 1.66 \mathrm{U} / \mathrm{liter}$. This did not differ significantly from control values of $6.47 \pm 2.10$ U/liter. The activity of lactic dehydrogenase in perfusate during constant infusion of protoporphyrin was $15.76 \pm 5.41 \mathrm{U} /$ liter and after the bolus dose of protoporphyrin, $33.36 \pm 14.49 \mathrm{U} /$ liter. This was not significantly different from the control value of $17.53 \pm 11.80 \mathrm{U} /$ liter.

Histopathological studies. The histopathology of tissue perfused with and without protoporphyrin was studied by light, fluorescent, polarizing, scanning, and transmission electron microscopy. Light microscopic examination of tissue sections stained with hematoxylin and eosin did not reveal significant differences between the control and protoporphyrinperfused livers. The lobular architecture was preserved and neither parenchymal necrosis nor edema were present. Ultraviolet microscopy of unstained tissue sections did not reveal fluorescence in livers perfused without protoporphyrin. In contrast, tissue sections from livers perfused with protoporphyrin showed a diffuse, bright, red fluorescence in the cytoplasm of hepatic parenchymal cells and canaliculi. Examination of tissue sections with polarizing microscopy did not reveal birefringent material in livers perfused with or without protoporphyrin. Scanning electron microscopy of tissue sections from livers perfused with protoporphyrin demonstrated normal sinusoidal and parenchymal architure. However, when compared with control livers, microvilli in the canaliculi appeared less numerous. Transmission electron microscopy showed minor mitochondrial distortions, prominent pericanalicular autophagic lysosomal bodies, and occasional cytoplasmic vacuoles in both groups. The

TABLE III

Regional Lobar Distribution of Radiolabeled Microspheres

\begin{tabular}{lccc}
\hline \multicolumn{1}{c}{ Liver Lobe } & $\begin{array}{c}\text { Control }(n=4) \\
\text { P/C }\end{array}$ & $\begin{array}{c}\text { Protoporphyrin } \\
\text { P/C }(n=4)\end{array}$ & $P$ \\
\hline Left & $0.73 \pm 0.21$ & $0.73 \pm 0.26$ & $<0.99$ \\
Median & $0.74 \pm 0.18$ & $1.41 \pm 0.32$ & $<0.20$ \\
Caudate & $0.73 \pm 0.12$ & $0.87 \pm 0.20$ & $<0.60$ \\
Right (pyramidal) & $0.71 \pm 0.17$ & $1.10 \pm 0.15$ & $<0.20$
\end{tabular}

The ratio of peripheral/central $(\mathrm{P} / \mathrm{C})$ radiolabeled microspheres was determined as described in Methods. Tissue samples were counted for $1 \mathrm{~min}$ and expressed per milligram liver. The $\mathrm{P} / \mathrm{C}$ ratio represents the mean $\pm S E M$. No differences were demonstrated between the two groups as indicated by the $P$ values.

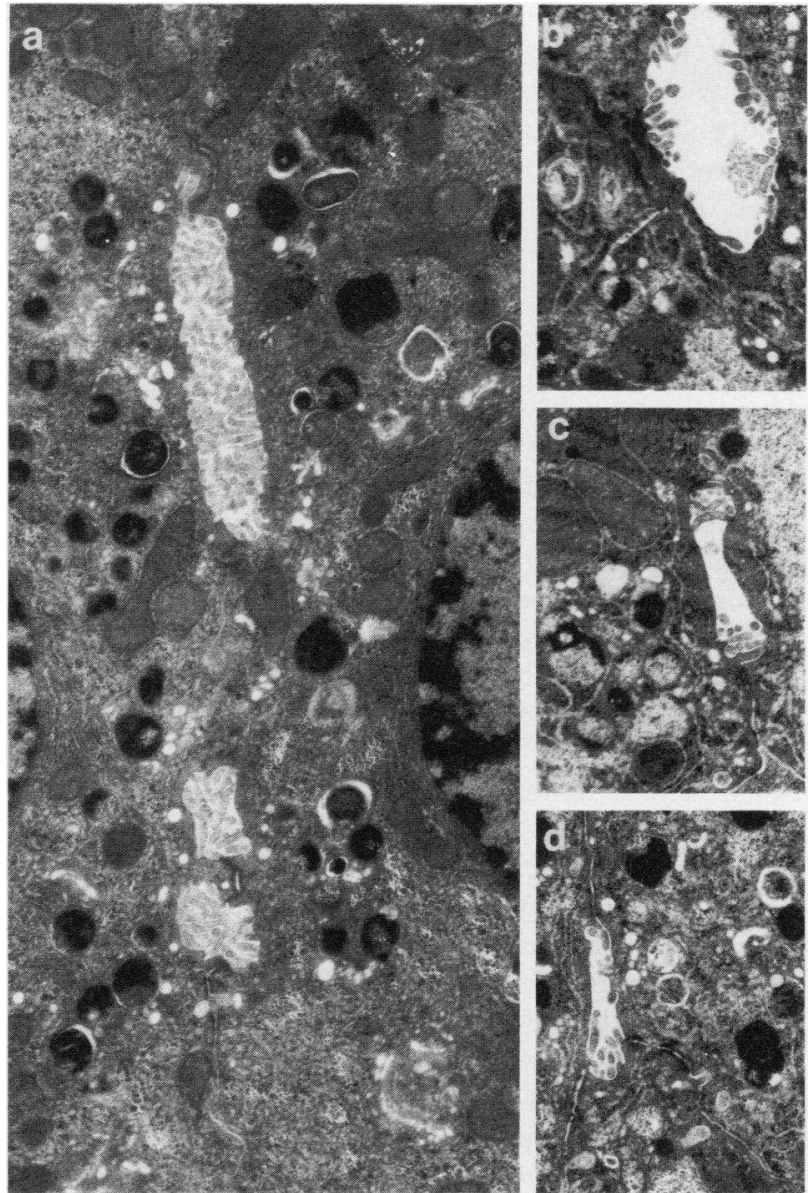

FIGURE 7 Transmission electron photomicrographs that show bile canaliculi from in situ rat liver perfusions without NaTC, as described in Methods. (a) Section from a control liver perfused for $70 \mathrm{~min}$ without protoporphyrin. Canaliculi appear in longitudinal (top) and cross-sections (bottom). Microvilli are prominent and fill the lumen $(\times 13,750)$. (b, c, and d) Sections from protoporphyrin-perfused rat livers during maximal canalicular protoporphyrin secretion which represent the range of abnormalities observed. The canaliculus in section $b$ displays less pronounced changes with moderate distortion and loss of microvilli. Section d shows the least change but loss of microvilli is still evident $(\times 13,750)$.

portal tracts, hepatic veins, and large bile ducts appeared normal. In contrast, the canaliculi of protoporphyrin-perfused livers, compared to controls, were dilated and distorted (Fig. 7). The microvilli of the canaliculi often appeared short, and irregularly shaped; occasionally they were almost totally absent. These observations were confirmed by a quantitative assessment of the volume density of the biliary space in which 33 canaliculi from controls $(n=3)$ and 37 canaliculi from protoporphyrin-perfused livers $(n=3)$ were compared. The relative canalicular volume, expressed as a percentage of lobular space, was significantly different $(P<0.01)$ between control 
(0.9\%) and protoporphyrin-perfused livers (2.0\%). These findings are consistent with canalicular abnormalities reported in cholestasis (48-50). No amorphous or crystalline material comparable to that reported in protoporphyric patients $(9,16,17,19)$ or mice treated with griseofulvin (20-22) was identified in the hepatocytes, canaliculi, or Kupffer cells.

\section{DISCUSSION}

The pathogenesis of liver disease in protoporphyric patients is poorly understood. Protoporphyrin has been presumed to be the culpable agent. However, based on available information, it is not possible to establish a pathophysiologic correlation between the amount of protoporphyrin accumulated in the liver and histopathological abnormalities. Severe protoporphyric liver disease is characterized by an apparent rapid onset and progression, with unusually high erythrocyte, plasma, and hepatic protoporphyrin concentrations. These features suggest that at some point, perhaps related to the insidious deposition of protoporphyrin, hepatic impairment restricts elimination of protoporphyrin, facilitates its rapid accumulation and accelerates the liver disease. Eventually, protoporphyrin accumulation may be accelerated by a reduction in bile flow.

Cholestasis is a major histopathologic feature of protoporphyric liver disease; indeed, it has been referred to as "protoporphyrastasis" (19) because crystalline deposits of protoporphyrin have been observed to occlude canaliculi. This finding is emphasized by some investigators who hypothesize that precipitation of protoporphyrin in canaliculi may initiate development of the liver injury (8). Data to support this hypothesis, however, have not been presented. Therefore, the unexpected observation that bile flow was reduced in rat livers perfused with solutions containing protoporphyrin during experiments designed to determine the threshold of canalicular transport was of particular interest and stimulated further studies to examine this phenomenon.

The isolated perfused rat liver studies presented in this report employed a recirculating, membraneoxygenated, hemoglobin-free perfusate system with precisely controlled conditions. Metabolic and histologic studies assured viability and maintenance of function. Relative homogeneity of hepatic perfusion was demonstrated by technetium-labeled microsphere studies. Ultraviolet microscopy revealed diffuse red fluorescence in hepatic cells and canaliculi, which indicated that protoporphyrin was not sequestered within sinusoidal cells.

Protoporphyrin was found to significantly reduce bile flow, even during infusion of NaTC. That the inhibition of bile flow was a result of reduction of the BAIF of bile flow was indicated by two observations. Firstly, biliary bile acid secretion was not significantly different between control and protoporphyrinperfused livers. Secondly, linear regression analysis, which correlated biliary bile acid secretion and bile flow, revealed a significant difference between the $y$-intercepts of the control group and protoporphyrinperfused group without altering their slopes (Fig. 4). The degree of inhibition of bile flow was shown to be dose-related. However, further kinetic analyses are necessary to determine the relationship of protoporphyrin load to hepatic accumulation and cholestasis.

The mechanisms mediating the reduction of BAIF of bile flow in these studies is unknown. Based on the lack of significant difference in perfusate enzyme activities between control and protoporphyrin-perfused livers, it seems clear that cholestasis did not result from a nonspecific cellular injury. The contribution of altered regional hepatic perfusion to the inhibition of bile flow is less clear. Reduction of perfusate flow rate has been associated with both inhibition of bile flow (40) and a transient, relative decrease of peripheral hepatic flow (51). In the current studies, flow rate was maintained by a pump system and did not vary. The radionuclide liver scans of protoporphyrin-perfused livers appeared less homogeneous than controls. However, the peripheral/ central ratio of hepatic flow was not different. Normally, regional distribution of hepatic flow is quite variable (52) and unfortunately, the convenience of a peripheral/central flow ratio does not necessarily reflect effective acinar perfusion critical to bile formation. Therefore, on the basis of these data alone, the possibility that altered hepatic flow contributed to the decrease in bile flow cannot be excluded. Decreased perfusion rates, however, have not produced canalicular abnormalities (53), a prominent finding in the present studies.

Recent investigations suggest that the regulation of BAIF of bile flow may be governed by a multiplicity of complex, interdependent factors including liver plasma membrane NaK ATPase (54-56), bile acids $(57,58)$, canalicular membrane fluidity and viscosity $(59,60)$, and the microfilament apparatus of the canalicular secretory system (61). In this regard, a decrease in liver surface membrane $\mathrm{NaK}$ and $\mathrm{Mg}$ ATPase activity in protoporphyrin-perfused livers has recently been observed (62). Since protoporphyrin is known to penetrate and alter the physiochemical characteristics of monolayers of a variety of proteins and lipids (63), it seems reasonable to speculate that it may similarly affect lipoprotein components of the canalicular secretory apparatus.

The histopathologic studies of protoporphyrin- 
perfused livers revealed three findings that deserve comment. Firstly, light microscopy was essentially normal. This finding was not unexpected in view of the acute nature of these experiments. Secondly, electron microscopy revealed dilatation and distortion of canaliculi with effacement of microvilli. This occurred in conjunction with the reduction of bile flow. Thirdly, neither amorphous nor crystalline deposits of protoporphyrin were found in hepatocytes or canaliculi. This observation is remarkable because it indicates that the deleterious effects of protoporphyrin do not simply result from precipitation within the hepatocytes and canalciuli.

In summary, the present studies provide evidence that perfusion of rat livers with solutions containing protoporphyrin significantly inhibited the BAIF of bile flow. This cholestatic effect was associated with dilatation, distortion, and effacement of hepatic canaliculi in the absence of demonstrable cytoplasmic or canalicular deposits of protoporphyrin. The precise mechanisms for these phenomena are unknown. These observations should not be construed to explain the pathogenesis of the hepatic disease in protoporphyria. Rather, they provide direct evidence that protoporphyrin has hepatotoxic properties that affect the canalicular secretory system, and suggest that the pathophysiologic basis of hepatic lesions in protoporphyria is more complicated than previously thought.

\section{ACKNOWLEDGMENTS}

The authors gratefully acknowledge the secretarial assistance of Sylvia Gregg and the technical assistance of Phillip Gray, Susan Coffin, and Jeanette Taylor. Dr. James Kushner and Dr. Bruce Burnham provided particularly valuable counsel. Liver scanning and gamma counting were performed in the Department of Nuclear Medicine, University of Utah Medical Center, with the assistance of Fred Datz, M.D. and Mr. Paul Christian.

This work was supported, in part, by the Veterans Administration.

\section{REFERENCES}

1. Magnus, I. A., A. Jarrett, T. A. J. Prankerd, and C. Rimington. 1961. Erythropoietic protoporphyria - a new syndrome with solar urticaria due to protoporphyrinemia. Lancet. II: 448-451.

2. Bloomer, J. R., H. L. Bonkowsky, P. S. Ebert, and M. J. Mahoney. 1976. Inheritance in protoporphyria. Comparison of heme synthetase activity in skin fibroblasts with clinical features. Lancet. II: 226-228.

3. Bonkowsky, H. L., J. R. Bloomer, P. S. Ebert, and M. J. Mahoney. 1975. Heme synthetase deficiency in human protoporphyria. Demonstration of the defect in liver and cultured skin fibroblasts. J. Clin. Invest. 56: 1139-1148.

4. Bloomer, J. R., D. A. Brenner, and M. J. Mahoney. 1977. Study of factors causing excess protoporphyrin accumulation in cultured skin fibroblasts from patients with protoporphyria. J. Clin. Invest. 60: 1354-1361.

5. Bottomly, S. S., M. Tanake, and M. A. Everett. 1975.
Diminished erythrocyte ferrochelatase activity in protoporphyria. J. Lab. Clin. Med. 86: 126-131.

6. Poh-Fitzpatrick, M. B. 1977. Erythropoietic porphyrias: current mechanistic, diagnostic and therapeutic considerations. Semin. Hematol. 14: 211-219.

7. DeLeo, V. A., M. Poh-Fitzpatrick, M. Mathews-Roth, and L. C. Harber. 1976. Erythropoietic protoporphyria, 10 years experience. Am. J. Med. 60: 8-22.

8. Cripps, D. J., and R. J. Sheurer. 1965. Hepatobiliary changes in erythropoietic protoporphyria. Arch. Pathol. 80: 500-508.

9. Bloomer, J. R., M. J. Phillips, D. L. Davidson, and G. Klatskin. 1975. Hepatic disease in erythropoietic protoporphyria. Am. J. Med. 58: 869-882.

10. Cripps, D. J., L. A. Gilbert, and S. S. Goldfarb. 1977. Erythropoietic protoporphyria: juvenile protoporphyrin hepatopathy, cirrhosis, and death. J. Pediatr. 91: 744-745.

11. Cripps, D. J., and S. S. Goldfarb. 1978. Erythropoietic protoporphyria: hepatic cirrhosis. Br.J. Dermatol. 98: 349-354.

12. Singer, J. A., A. G. Plant, and M. M. Kaplan. 1978. Hepatic failure and death from erythropoietic protoporphyria. Gastroenterology. 74: 588-591.

13. Eales, L., R. S. Day, and N. R. Pimstone. 1978. Protoporphyrin (proto)-determined hepatopathy in a South African Jewish family. Ann. Clin. Res. 10: 205-213.

14. Donaldson, E. M., A. J. McCall, I. A. Magnus, J. R. Simpson, R. A. Caldwell, and T. Hargreaves. 1971. Erythropoietic protoporphyria: two deaths from hepatic cirrhosis. Br. J. Dermatol. 84: 14-24.

15. Bloomer, J. R. 1979. Pathogenesis and therapy of liver disease in protoporphyria. Yale J. Biol. Med. 52: $39-48$.

16. Bruguera, M., J. E. Esquerda, J. M. Mascaro, and J. Pinol. 1976. Erythropoietic protoporphyria: a light, electron, and polarizing microscopic study of the liver in 3 patients. Arch. Pathol. Lab. Med. 100: 587-589.

17. Pimstone, N. R., B. L. Webber, G. H. Blekkenhorst, and L. Eales. 1976. The hepatic lesion in protoporphyria: preliminary studies of heme metabolism, liver structure, and ultrastructure. Ann. Clin. Res. 8 (Suppl 17): 122-32.

18. Klatskin, G., and J. R. Bloomer. 1974. Birefringence of hepatic pigment deposits in erythropoietic protoporphyria. Gastroenterology. 67: 294-302.

19. Kniffen, J. C., and F. S. Porter. 1969. Intrahepatic porphyrastasis in erythropoietic protoporphyria. Clin. Res. 17: 26. (Abstr.)

20. Matilla, A., and E. A. Molland. 1975. A light and electron microscopic study of the liver in a case of erythropoietic protoporphyria and in griseofulvin-induced prophyria in mice. J. Clin. Pathol. 27: 698-709.

21. Gschnait, F., K. Konrad, H. Honigsmann, H. Denk, and K. Wolff. 1975. Mouse model for protoporphyria. I. The liver and hepatic protoporphyrin crystals. J. Invest. Dermatol. 65: 290-299.

22. Yokoo, H., R. M. Craig, T. R. Harwood, and C. Cochrane. 1979. Griseofulvin-induced cholestasis in Swiss albino mice. Gastroenterology. 77: 1082-1087.

23. Poh-Fitzpatrick, M. B., and A. A. Lamola. 1977. Comparative study of protoporphyrins in erythropoietic protoporphyria and griseofulvin-induced murine protoporphyria: binding affinities, distribution, and fluorescent spectra in various blood fractions. J. Clin. Invest. 60: $380-389$.

24. Lamon, J. M., M. B. Poh-Fitzpatrick, and A. A. Lamola with B. C. Frykholm, M. L. Freeman, and F. H. Doleiden. 
1980. Hepatic protoporphyrin production in human protoporphyria. Effects of intravenous hematin and analysis of erythrocyte protoporphyrin distribution. Gastroenterology. 79: 115-125.

25. Ruth, G. R., S. Schwartz, and B. Stephenson. 1977. Bovine protoporphyria: the first non-human model of this hereditary photosensitizing disease. Science (Wash. D. C.). 198: 199-201.

26. Avner, D. L., and M. M. Berenson. 1979. Hepatic extraction and biliary excretion of protoporphyrin. Gastroenterology. 76: 1274. (Abstr.)

27. Avner, D. L., and M. M. Berenson. 1979. Protoporphyrin-induced cholestasis. Gastroenterology. 77 (5): A2. (Abstr.)

28. Miller, L. L., C. G. Bly, M. L. Watson, and W. F. Bale. 1951. A direct study of the isolated perfused rat liver with the aid of lysine- $\xi-C^{14}$.J. Exp. Med. 94: 431-453.

29. Hems, R., B. D. Ross, M. N. Berry, and H. A. Krebs. 1966. Gluconeogenesis in the perfused rat liver. Biochem. J. 101: 284-292.

30. Krebs, H. A., and K. Henseleit. 1932. Untersuchungen uber die larnstoffbildung im tierkorpar. Hoppe-Seyler's Physiol. Chem. 210: 33-66.

31. Hofmann, A. F. 1964. Thin-layer chromatography of bile acids and their derivatives. In New Biochemical Separations. A. T. James and L. J. Morris, editors. Van Nostrand Reinhold Company, New York. 261.

32. Mitzkat, H. J., and U. Meyer. 1973. Metabolic state of isolated perfused rat liver and model-induced metabolism modifications. In Isolated Liver Perfusion and Its Applications. I. Bartosek, A. Guaitani, and L. L. Miller, editors. Raven Press, New York. 79-86.

33. Ross, B. D. 1972. Perfusion Techniques in Biochemistry. Clarendon Press, Oxford. 118.

34. Boyer, J. L. 1971. Canalicular bile formation in the isolated perfused rat liver. Am. J. Physiol. 221: 1156-1163.

35. Slein, M. W. 1963. Methods of Enzymatic Analysis. H. U. Bergmeyer, editor. Academic Press, New York. 117.

36. Grisham, J. W., W. Nopanitaya, J. Compagne, and A. E. H. Nagel. 1975. Scanning electron microscopy of normal rat liver: the surface structure of its cells and tissue components. Am. J. Anat. 144: 295-322.

37. Tanikawa, K. 1968. Ultrastructural aspects of the liver and its disorders. Igaku Shoin, Ltd., Tokyo.

38. Avner, D. L., and M. M. Berenson. 1979. Bile aciddependent biliary protoporphyrin excretion. Gastroenterology. 77(5): A2. (Abstr.)

39. İwata, T., and K. Yamasaki. 1964. Enzymatic determination and thin layer chromatography of bile acids in blood. J. Biochem. (Tokyo). 56: 424-431.

40. Tavoloni, N., J. S. Reed, and J. L. Boyer. 1978. Hemodynamic effects on determinants of bile secretion in isolated rat liver. Am. J. Physiol. 234: E584-E592.

41. Henry, R. J., N. Chiamori, O. J. Golub, and S. Berkman. 1960. Revised spectrophotometric methods for the determination of glutamic-oxalacetic transaminase, glutamic-pyruvic transaminase, and lactic acid dehydrogenase. Am. J. Clin. Pathol. 34: 381-398.

42. Amador, E., and W. E. C. Wacker. 1962. Serum glutamic-oxaloacetic transaminase activity; a new modification and analytical assessment of current assay techniques. Clin. Chem. 8: 343-350.

43. Amador, E., L. E. Dorfman, and W. E. C. Wacker. 1963. Serum lactic dehydrogenase activity: an analytical assessment of current assays. Clin. Chem. 9: 391-399.

44. Loud, A. V. 1968. A quantitative stereological description of the ultrastructure of normal rat liver parenchymal cells. J. Cell. Biol. 37: 27-46.
45. Weibel, E. R., G. S. Kistler, and W. F. Scherle. 1966. Practical stereological methods for morphometric cytology. J. Cell Biol. 30: 23-38.

46. Weibel, E. R., W. Staubli, H. R. Gnagi, and F. A. Hess 1969. Correlated morphometric and biochemical studies on the liver cell. J. Cell Biol. 42: 68-91.

47. Colton, T. 1974. Statistics in Medicine. Little, Brown and Company. Boston.

48. Schaffner, F., H. Popper, and V. Perez. 1960. Changes in bile canaliculi produced by norethandrolone: electron microscopic study of human and rat liver. J. Lab. Clin. Med. 56: 623-628.

49. Schaffner, F. 1965. Morphologic studies on bile secretion. Am. J. Dig. Dis. 10: 99-115.

50. Jones, A. L., D. L. Schmucker, J. S. Mooney, R. D. Adler, and R. K. Ockner. 1976. Morphometric analysis of rat hepatocytes after total biliary obstruction. Gastroenterology. 71: 1050-1060.

51. Tavoloni, N., J. S. Reed, Z. Hruban, and J. L. Boyer. 1979. Effect of chlorpromazine on hepatic perfusion and bile secretory function in the isolated perfused rat liver. $J$. Lab. Clin. Med. 94: 726-741.

52. Daniel, P. M., and M. M. L. Prichard. 1951. Variations in the circulation of the portal venous blood within the liver. J. Physiol. 114: 521-537.

53. Hruban, A., N. Tavoloni, J. S. Reed, and J. L. Boyer. 1978 Ultrastructural changes during cholestasis induced by chlorpromazine in the isolated perfused rat liver. Virchows Arch. B. Cell Pathol. 26: 289-305.

54. Erlinger, S., and D. Dhumeaux. 1974. Mechanisms and control of secretion of bile water and electrolytes. Gastroenterology. 66: 281-304.

55. Layden, T. J., and J. L. Boyer. 1976. The effect of thyroid hormone on bile salt independent flow and $\mathrm{Na}^{+}, \mathrm{K}^{+}$-ATPase activity in liver plasma membranes enriched in bile canaliculi.J. Clin. Invest. 59: 1009-1018.

56. Simon, F. R., E. Sutherland, and L. Accatino. 1977 Stimulation of hepatic sodium and potassium-activated adenosine triphosphatase activity by phenobarbital. Its possible role in regulation of bile flow. J. Clin. Invest. 59: 849-861.

57. Wannagat, F. J., R. D. Adler, and R. K. Ockner. 1978 Bile acid-induced increase in bile acid-independent flow and plasma membrane NaK-ATPase activity in rat liver. J. Clin. Invest. 61: 297-307.

58. Paumgartner, G. 1977. Physiology of bile secretion: bile acid-dependent bile flow. In Liver and Bile. L. Bianchi, W. Gerok, and K. Sickinzer, editors. University Park Press, Baltimore, Md. 45-51.

59. Davis, R. A., F. Kern, Jr., R. Showalter, E. Sutherland, M. Sinensky, and F. R. Simon. 1978. Alteration of hepatic $\mathrm{Na}^{+}, \mathrm{K}^{+}$-ATPase and bile flow by estrogen: effects on liver surface membrane lipid structure and function. Proc. Natl. Acad. Sci. U. S. A. 75: 4130-4134.

60. Keefe, E. B., B. F. Scharschmidt, N. M. Blankenship, and R. K. Ockner. 1979. Studies of relationships among bile flow, liver plasma membrane NaK-ATPase, and membrane microviscosity in the rat. J. Clin. Invest. 64: 1590-1598.

61. Elias, E., and J. L. Boyer. 1979. Chlorpromazine and its metabolites alter polymerization and gelatin of actin. Science (Wash. D. C.). 206: 1404-1406.

62. Avner, D. L., and M. M. Berenson. 1980. Protoporphyrin-induced cholestasis is associated with reduced hepatic membrane Na-K and Mg-ATPase activity. Gastroenterology. 79: 1002. (Abstr.)

63. Stenhagen, E., and E. K. Rideal. 1939. The interaction between porphyrins and lipoid and protein monolayers. Biochem. J. 33: 1591-1598. 